\title{
Bradycardia associated with remdesivir therapy for COVID-19 in a 59-year-old man
}

\author{
Leora Branfield Day MD, Husam Abdel-Qadir MD PhD, Michael Fralick MD PhD SM
}

Cite as: CMAJ 2021 April 26;193:E612-5. doi: 10.1503/cmaj.210300

$\mathbf{A}$ 59-year-old man presented to hospital with cough and shortness of breath after a positive polymerase chain reaction test for SARS-CoV-2, 1 week earlier. He had no past medical history, a normal body mass index, and was not taking any prescription or over-the-counter medications. He did not smoke cigarettes, drink alcohol or take any recreational drugs. He lived in a multigenerational home and worked as a jeweller.

On physical examination, his vital signs were normal (blood pressure $129 / 74 \mathrm{~mm} \mathrm{Hg}$, heart rate 89 beats/min, body temperature $36.9^{\circ} \mathrm{C}$ ), apart from hypoxia requiring $2 \mathrm{~L}$ of oxygen via nasal prong cannula. He was not in respiratory distress and his cardiovascular, respiratory and abdominal examinations were normal. The results of routine laboratory testing showed decreased lymphocyte count $\left(1.1 \times 10^{9} / \mathrm{L}\right)$ and an elevated C-reactive protein level $(70 \mathrm{mg} / \mathrm{L})$. Platelet count and hemoglobin, creatinine, highsensitivity troponin and liver enzyme (alanine aminotransferase $[A L T]$ ) levels were normal. His electrocardiogram (ECG) showed normal sinus rhythm with a heart rate of 79 beats/min (Figure 1), and his chest radiograph showed normal cardiac silhouette and moderate opacification in the mid to lower lung zones bilaterally, in keeping with COVID-19.

The patient was admitted to hospital and started on dexamethasone $6 \mathrm{mg}$ daily and enoxaparin $40 \mathrm{mg}$ subcutaneous daily for prophylaxis of deep vein thrombosis. He was also enrolled in the World Health Organization (WHO) Solidarity trial, ${ }^{1}$ as well as the Convalescent Plasma for Hospitalized Adults With COVID-19 Respiratory Illness (CONCOR-1) and Prone Positioning for Patients on General Medical Wards With COVID19 (COVID Prone) trials and randomized to remdesivir, convalescent plasma and prone positioning. These interventions were started on day 2 of his hospital stay. Convalescent plasma was administered on day 2 and remdesivir was administered as a loading dose of $200 \mathrm{mg}$ intravenously (IV) on day 2, followed by $100 \mathrm{mg}$ IV on day 3 and daily thereafter. On day 4 of his stay in hospital (i.e., after his third dose of remdesivir), he developed sinus bradycardia with a heart rate of 50 beats/min (confirmed on ECG, Figure 2). He had generalized weakness, fatigue and headache, but did not experience lightheadedness or loss of consciousness. He had no constipation, nausea or pain, and no symptoms suggestive of increased vagal tone. Bloodwork was notable for an elevated ALT (127 unit/L, upper limit of normal 40), normal electrolytes

\section{KEY POINTS}

- Remdesivir is one of the most commonly prescribed medications for patients admitted to hospital with COVID-19.

- Sinus bradycardia has been associated with remdesivir in the treatment of patients with COVID-19.

- An association between remdesivir and bradycardia is particularly relevant for many patients who are admitted to hospital with COVID-19 who have other risk factors for bradycardia including older age, cardiovascular disease and concomitant $\beta$ - blocker use.

(sodium, potassium, bicarbonate, calcium, magnesium, phosphate), thyroid-stimulating hormone and C-reactive protein. The fourth dose of remdesivir was held, given his bradycardia and elevated ALT. After we stopped the remdesivir, the patient's heart rate began to increase and on day 7 , his heart rate had increased to 62 beats/min, his ALT was 133 unit/L and he was discharged home (Figure 3). We did not restart the remdesivir.

\section{Discussion}

Remdesivir was approved through an emergency use authorization by the United States Federal Drug Administration (FDA) for the treatment of patients with COVID-19 requiring admission to hospital. ${ }^{2}$ Health Canada approved remdesivir for patients in hospital with severe COVID-19 with pneumonia requiring supplemental oxygen. ${ }^{3}$

The 2 largest randomized controlled trials (RCTs) evaluating the efficacy and safety of remdesivir are the Adaptive COVID-19 Treatment Trial (ACTT-1) and the World Health Organization Solidarity Trial. ${ }^{1,4}$ ACTT-1 showed that patients randomized to remdesivir $(n=541)$ recovered faster than patients randomized to placebo (i.e., $15 \mathrm{~d}$ v. $10 \mathrm{~d}, p<0.001$ ). ${ }^{4}$ Solidarity demonstrated that patients randomized to remdesivir $(n=2750)$ had a mortality rate similar to those randomized to standard of care. ${ }^{1}$ Despite no evidence of a reduction in mortality in the Solidarity trial, remdesivir is one of the most commonly prescribed medications for people admitted to hospital with COVID-19. It is estimated that more than 2 million doses of remdesivir have been administered worldwide during the COVID-19 pandemic. ${ }^{6}$ 


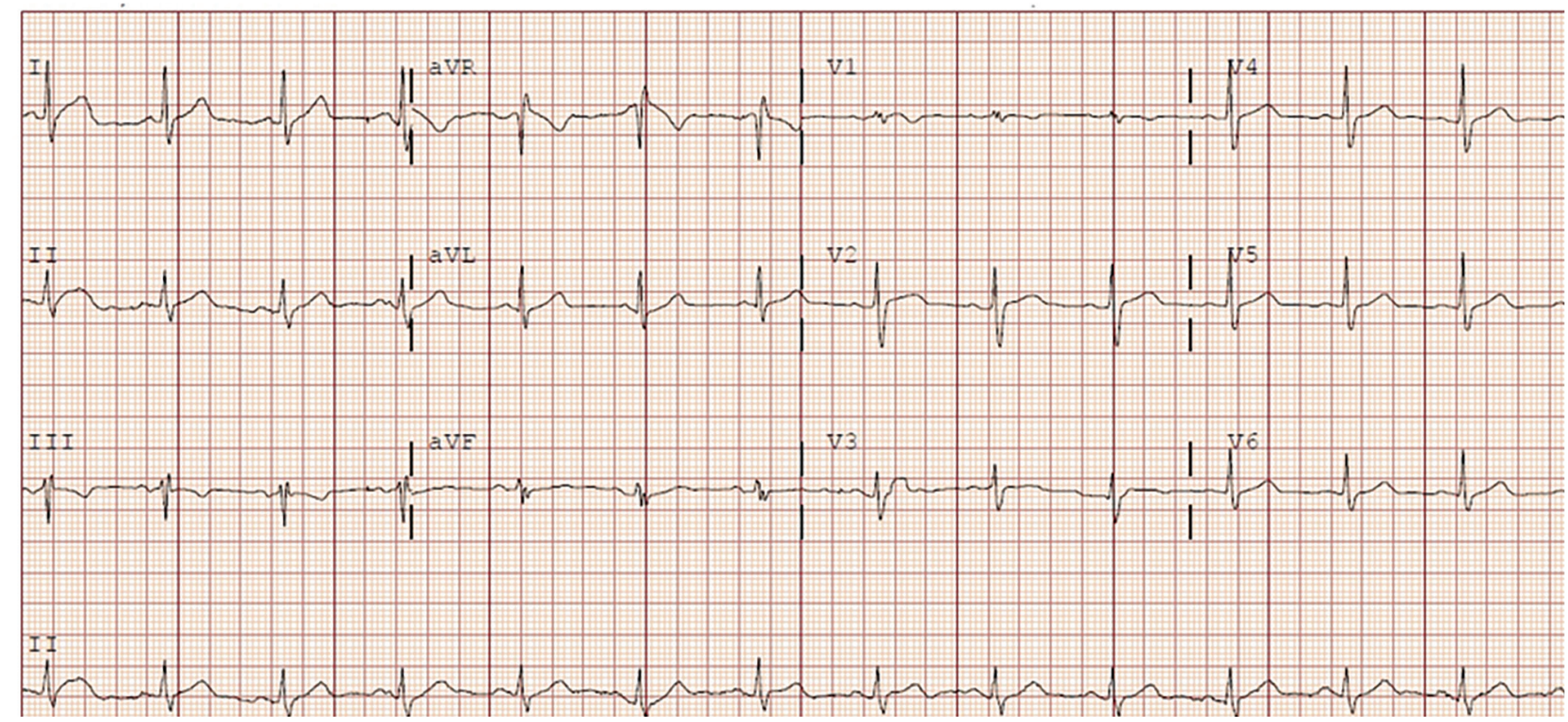

Figure 1: Electrocardiogram of a 59-year-old man before remdesivir treatment, showing normal sinus rhythm.

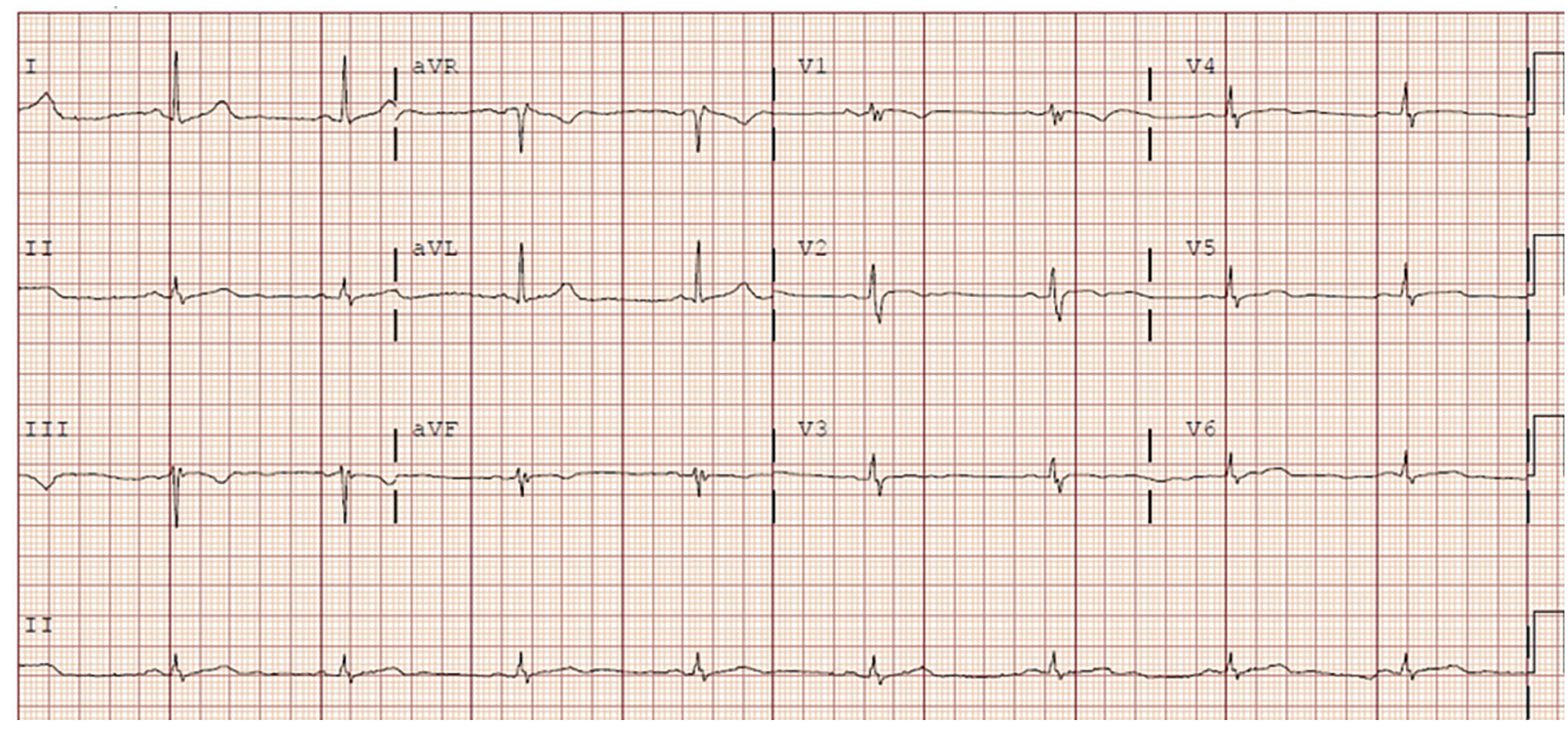

Figure 2: Electrocardiogram after dose 3 of remdesivir treatment, showing sinus bradycardia.

Remdesivir is an intravenous prodrug of an adenosine analogue originally developed in research programs in hepatitis $C$ and respiratory syncytial virus and later refined for the treatment of Ebola. It inhibits viral ribonucleic acid (RNA) polymerase and is active against a broad range of viruses, including the Middle East respiratory syndrome coronavirus, SARS and SARS-CoV-2. ${ }^{4}$ It is generally well tolerated although transaminitis, which primarily manifests as an elevated ALT, is a common adverse effect seen in both patients and healthy volunteers receiving remdesivir. ${ }^{2}$

Recent case reports suggest that remdesivir may also cause bradycardia., 5,8 Our patient had both an elevated ALT and sinus bradycardia. Although there were no adverse clinical sequelae of the latter, if remdesivir does cause bradycardia, it will be particularly relevant for patients who are admitted to hospital with COVID-19 and have other risk factors for bradycardia (e.g., older age, concomitant $\beta$-blocker use). Our discussion will focus primarily on the potential association between remdesivir and bradycardia and briefly summarize the efficacy and safety data for remdesivir.

Common adverse events for remdesivir (1\%-10\% incidence) include rash, headache, nausea, diarrhea, and moderate to severely elevated transaminases. ${ }^{2,4}$ Rarely, hypersensitivity reactions (infusion related and anaphylaxis), hypotension and renal impairment may also occur (< $0.1 \%$ incidence). In ACTT-1, arrhythmias (other than ventricular fibrillation and tachycardia, supraventricular 


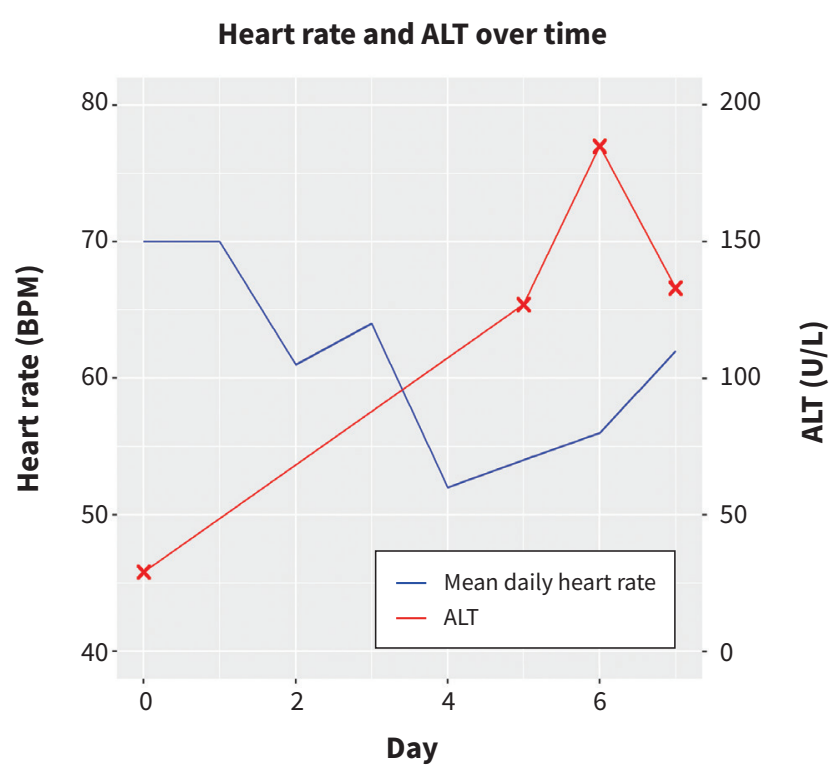

Figure 3: Changes in mean daily heart rate (beats per minute [BPM]) and alanine aminotransferase (ALT; units/L) from day of admission to discharge. Remdesivir was started on day 2 and discontinued on day 5.

tachycardias and atrial fibrillation) affected $0.2 \%$ of patients receiving remdesivir, compared with no reported events in the placebo group. Data specifically on bradycardia were not reported.

Other potential cardiac complications described with remdesivir include supraventricular tachycardia, which was reported in $0.6 \%$ of patients in the ACTT- 1 experimental group (compared with $0.4 \%$ in the control group) and serious atrial fibrillation in $0.9 \%$ of patients in the experimental group (compared with $0.2 \%$ in the control group). There was also 1 case of cardiac arrest during remdesivir therapy in $0.6 \%$ of patients in $1 \mathrm{RCT}$ of remdesivir versus placebo (compared with no events in the control group). ${ }^{7}$ ACTT-1 reported cardiac arrests in $1.9 \%$ of patients receiving remdesivir compared with $1.4 \%$ receiving placebo. Additionally, in the initial clinical trial evaluating remdesivir for the treatment of Ebola, 1 patient out of 175 had hypotension leading to cardiac arrest after remdesivir, which was deemed potentially related to the drug. ${ }^{7}$

Although neither ACTT-1 nor Solidarity identified bradycardia as a potential adverse effect, clinical trials are generally underpowered to detect uncommon adverse events. ${ }^{9}$ Recent case reports have described 4 cases of sinus bradycardia in patients with COVID-19 who received remdesivir (Table 1). ${ }^{5,7,8}$ Gubitosa and colleagues described a case of a 54-year-old woman with a baseline left bundle branch block of unknown cause, who developed marked sinus bradycardia to 38 beats/min within 24 hours after her first dose of remdesivir for COVID-19, along with mild widening of the QRS and lengthening of her QT interval (QTc $496 \mathrm{~ms}$ from $440 \mathrm{~ms}$ ). Her bradycardia worsened to a nadir of 34 beats/min after her third dose and she required atropine temporarily for angina and hypotension. ${ }^{7}$ Sanchez-Codez and colleagues described a case of severe sinus bradycardia (heart rate 40 beats/min) in an otherwise healthy 13-year-old boy after he received his third dose of remdesivir. ${ }^{5}$ The bradycardia resolved within 24 hours of discontinuing remdesivir. Transient sinus bradycardia associated with QT prolongation (QTc $439 \mathrm{~ms}$ to $555 \mathrm{~ms}$ ) was also reported in a 26-year-old woman with a past medical history of obesity, who was receiving remdesivir for treatment of COVID-19. A 77-year-old woman had similar transient bradycardia after administration of remdesivir. ${ }^{8}$ Additionally, the FDA reported 9 cases of bradycardia with remdesivir use for COVID-19 between January and June 2020, which were not in the context of an infusion reaction. ${ }^{10}$

Table 1: Reports of sinus bradycardia in patients with COVID-19 receiving remdesivir

\begin{tabular}{|c|c|c|c|c|c|c|c|}
\hline Study & $\begin{array}{l}\text { Age, } \\
\text { yr; sex }\end{array}$ & $\begin{array}{c}\text { Bradycardia } \\
\text { onset } \\
\text { relative to } \\
\text { remdesivir } \\
\text { initiation }\end{array}$ & $\begin{array}{l}\text { Risk factors } \\
\text { for } \\
\text { bradycardia }\end{array}$ & $\begin{array}{l}\text { Lowest } \\
\text { heart } \\
\text { rate, } \\
\text { BPM }\end{array}$ & $\begin{array}{c}\text { Other ECG } \\
\text { abnormalities }\end{array}$ & Clinical sequelae & $\begin{array}{l}\text { Time to recovery } \\
\text { after drug } \\
\text { discontinuation }\end{array}$ \\
\hline Gupta et al. ${ }^{8}$ & $26 ; F$ & $\begin{array}{l}\text { Day 2, nadir } \\
\text { on day } 3\end{array}$ & None & 40 & $\begin{array}{l}\text { Prolonged QT/QTc to } \\
628 / 555 \mathrm{~ms}^{\star} \text { (from } \\
388 / 439 \mathrm{~ms} \text { ) with } \\
\text { T-wave abnormalities }\end{array}$ & Asymptomatic & Within $48-72 \mathrm{~h}$ \\
\hline Gupta et al. ${ }^{8}$ & $77 ; \mathrm{F}$ & Day 3 & Age & 48 & None & Asymptomatic & Within $48 \mathrm{~h}$ \\
\hline $\begin{array}{l}\text { Sanchez-Codez } \\
\text { et al. }{ }^{5}\end{array}$ & $13 ; M$ & Day 3 & None & 40 & None & Asymptomatic & Within $24 \mathrm{~h}$ \\
\hline 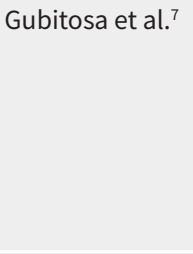 & $54 ; F$ & $\begin{array}{l}\text { Day 2, nadir } \\
\text { on day } 4\end{array}$ & None & 34 & $\begin{array}{l}\text { QRS widening to } \\
170 \mathrm{~ms} \text { (from } 168 \mathrm{~ms} \\
\text { before administration } \\
\text { and } 150 \mathrm{~ms} \text { baseline) } \\
\text { and QTc prolongation } \\
\text { to } 496 \mathrm{~ms} \text { (from } 440- \\
460 \mathrm{~ms}) \dagger\end{array}$ & $\begin{array}{l}\text { Angina and } \\
\text { hypotension } \\
\text { requiring atropine }\end{array}$ & Within $4 \mathrm{~d} \dagger$ \\
\hline Current case & 59; M & Day 3 & None & 50 & None & Asymptomatic & Within $72 \mathrm{~h}$ \\
\hline
\end{tabular}


There are several possible mechanisms for cardiac adverse effects with remdesivir. First, an active metabolite of remdesivir is similar to adenosine triphosphate, which has been shown to reduce sinus node automaticity through vagal stimulation, which could cause sinus bradycardia. ${ }^{11}$ Although remdesivir has a markedly high binding affinity for viral polymerases, any cross-reactivity with human mitochondrial RNA polymerase could lead to mitochondrial dysfunction, which is an established mechanism for drug-induced cardiotoxicity. ${ }^{5,8}$ Drug-induced cardiac myocyte cytotoxicity has been shown in in-vitro studies of cardiomyocytes derived from human stem cells treated with remdesivir. ${ }^{12}$ Choi and colleagues showed that the cytotoxic effects of remdesivir on cardiomyocytes increased over time, such that a longer duration of treatment (48 v. $24 \mathrm{~h}$ ) was associated with reduced cell viability. ${ }^{12}$ Additionally, as an adenosine analogue, remdesivir could affect atrioventricular nodal conduction, which could explain the QRS prolongation seen in previous cases. ${ }^{5,7,8}$ Further studies to evaluate these mechanisms and their effect specifically on sinoatrial node activity are needed.

In our patient, the bradycardia occurred soon after starting the medication (Figure 3 ) and improved within 48 hours of discontinuing it. He was on no other medications that would otherwise account for the bradyarrhythmia seen and there were no clinical features suggestive of heightened vagal tone. Although case reports cannot establish causality, this time course raises suspicion that remdesivir was a causative factor. Additionally, although bradycardia has been reported among patients with severe COVID19 , our patient did not present with bradycardia, and the bradycardia occurred after starting remdesivir when he was improving clinically. ${ }^{7,10}$ Furthermore, our patient had a score of 6 on the Naranjo Adverse Drug Reaction Probability Scale, a score that suggests a probable causative association between remdesivir and the bradycardia. ${ }^{13}$ We did not re-trial the medication because the patient was well enough to be discharged home.

\section{Conclusion}

Our case report adds to the literature on the association between remdesivir and bradycardia. This association is relevant, because remdesivir is one of the most commonly used medications to treat patients admitted to hospital with COVID-19. Although our patient did not have serious clinical sequelae, it is relevant for patients who are older or on medications known to cause bradycardia. After all, the mean age of patients admitted to hospital with COVID-19 is about 70 years, and many have cardiovascular disease or hypertension and often take $\beta$-blockers. ${ }^{2}$ Data from large cohort studies are needed to understand whether our case report represents a spurious finding or a true association.

\section{References}

1. WHO Solidarity Trial Consortium; Pan H, Peto R, Henao-Restrepo A-M, et al. Repurposed antiviral drugs for COVID-19: interim WHO Solidarity Trial results. N Engl J Med 2021;384:497-511.

2. Veklury summary review. Silver Spring (MD): US Food and Drug Administration, Center for Drug Evaluation and Research Pharmacovigilance Memorandum. U.S. Food and Drug Administration, Center for Drug Evaluation and Research; 2015. Available: www.accessdata.fda.gov/drugsatfda_docs/nda/2020/2147870rig1s000SumR.pdf (accessed 2021 Jan. 25).
3. Update on remdesivir: continued monitoring. Ottawa: Health Canada; modified 2020 Nov. 26. Available: www.canada.ca/en/health-canada/services/drugs-health -products/covid19-industry/drugs-vaccines-treatments/remdesivir-update.html (accessed 2021 Jan. 20).

4. Beigel JH, Tomashek KM, Dodd LE, et al.; ACTT-1 Study Group Members. Remdesivir for the treatment of COVID-19: final report. N Engl J Med 2020;383:1813-26.

5. Sanchez-Codez MI, Rodriguez-Gonzalez M, Gutierrez-Rosa I. Severe sinus bradycardia associated with remdesivir in a child with severe SARS-CoV-2 infection. Eur J Pediatr 2021 Jan. 23. [Epub ahead of print]. doi: 10.1007/s00431-021-03940-4.

6. O'Day D. Gilead Sciences. [Conference presentation]. Presentation at: 39th Annual J.P. Morgan Healthcare Conference. Available: http://investors. gilead.com/static-files/da2a6be6-1c7a-4769-aa73-8f00408c91a3 (accessed 2021 Apr. 1).

7. Gubitosa JC, Kakar P, Gerula C, et al. Marked sinus bradycardia associated with remdesivir in COVID-19: a case and literature review. JACC Case Rep 2020;2:2260-4.

8. Gupta AK, Parker BM, Priyadarshi V, et al. Cardiac adverse events with remdesivir in COVID-19 infection. Cureus 2020;12:e11132.

9. Fralick M, Kesselheim AS. Using real-world safety data in regulatory approval decisions: Sotagliflozin and the risk of diabetic ketoacidosis. Pharmacoepidemiol Drug Saf 2020;29:1322-4.

10. Veklury other review(s). Silver Spring (MD): US Food and Drug Administration, Center for Drug Evaluation and Research; 2020. Available: www.accessdata. fda.gov/drugsatfda_docs/nda/2020/2147870rig1s0000therR.pdf (accessed 2021 Feb. 4)

11. Pelleg A, Belhassen B. The mechanism of the negative chronotropic and dromotropic actions of adenosine 5 '-triphosphate in the heart: an update. $J$ Cardiovasc Pharmacol 2010;56:106-9.

12. Choi SW, Shin JS, Park SJ, et al. Antiviral activity and safety of remdesivir against SARS-CoV-2 infection in human pluripotent stem cell-derived cardiomyocytes. Antiviral Res 2020;184:104955.

13. Naranjo CA, Busto U, Sellers EM, et al. A method for estimating the probability of adverse drug reactions. Clin Pharmacol Ther 1981;30:239-45.

Competing interests: Michael Fralick is a co-investigator of the Solidarity clinical trial and has received grants from the Canadian Institutes of Health Research to support this work. Dr. Fralick is also a consultant for a start-up company, based at the Massachusetts Institute of Technology, that has developed a CRISPR-based point of care diagnostic test for coronavirus disease 2019. Husam Abdel-Qadir reports receiving personal fees from Amgen, outside the submitted work, and payments from the Canadian Vigour Centre (an academic research organization) to serve on the endpoint adjudication committee for the THEMIS trial, which was funded by AstraZeneca. No other competing interests were declared.

This article has been peer reviewed.

The authors have obtained patient consent.

Affiliations: Division of General Internal Medicine (Branfield Day, Fralick), Sinai Health System; Division of Cardiology (Abdel-Qadir), Women's College Hospital, Toronto, Ont.

Contributors: Leora Branfield Day and Michael Fralick contributed to the conception and design of the work and drafted the manuscript. All of the authors revised it critically for important intellectual content, gave final approval of the version to be published and agreed to be accountable for all aspects of the work.

Content licence: This is an Open Access article distributed in accordance with the terms of the Creative Commons Attribution (CC BY-NCND 4.0) licence, which permits use, distribution and reproduction in any medium, provided that the original publication is properly cited, the use is noncommercial (i.e., research or educational use), and no modifications or adaptations are made. See: https://creativecommons.org/ licenses/by-nc-nd/4.0/

Correspondence to: Michael Fralick, mike.fralick@mail.utoronto.ca 